\title{
КЛИНИЧЕСКИЙ СЛУЧАЙ УСПЕШНОГО ЛЕЧЕНИЯ COVID-19 \\ В ДОМАШНИХ УСЛОВИЯХ
}

\section{Савостьянов Владимир Владимирович, доктор медицинских наук}

Аннотация: в статье анализируются контроль за клиническим течением COVID-19 в условиях самоизоляиии и лечения в домашних условиях.

Ключевые слова: COVID-19, мониторинг, циффровой скрининг

Пациент В., 46 лет, заболел в ночь с 12 на 13 апреля 2020 года, когда испытал внезапную заложенность носа, потерю обоняния и резкую боль в горле в области правой миндалины. Заложенность носа устранял назальным спреем, против воспаления в горле использовал антисептический раствор йода с глицерином (раствор Люголя).

Утром 13 апреля начался сухой непродуктивный кашель. К вечеру появилась субфебрильная температура. В этот же день пациент В. самоизолировался для лечения на дому, подозревая у себя COVID-19.

Из анамнеза заболевания. 1 апреля 2020 года Пациент В. имел близкий контакт с медицинскими работниками одной из городских больниц, которые ранее оказывали помощь тяжёлым больным с COVID-19. Как выяснилось позднее, один из этих медицинских работников был инфицирован коронавирусом и госпитализирован для лечения в стационар.

В течении последующих дней с 1 по 13 апреля пациент В. отметил нарастающую слабость и потливость. В течении этого периода времени у пациента В. был зафиксирован катаральный конъюнктивит обоих глаз (лечение глазными каплями - диклофенак и левофлоксацин - в оба глаза 6 раз в день), а также гастрит (лечение омепрарзолом 20 мг 2 раза в день).

Из анамнеза жизни. Пациент В. ведёт активный образ жизни, не имеет вредных привычек и хронических заболеваний. Спортсмен-любитель. Тренируется по 4-5 раз в неделю, за тренировку пробегает 8-12км. Артериальное давление 125/75 мм рт.ст., пульс 5658 bpm, частота дыхания 4-6 rpm, рост 183 см, вес 84 кг.

Назначенное лечение. Ацетисалициловая кислота 500мг (шипучие таблетки) 3 раза в день; биологически активная добавка (цинк 5мг, аскорбиновая кислота 600мг) однократно днём; комплексный препарат в виде растворимого порошка для приготовления горячего напитка (фенилэфрина гидрохлорид 10мг, фенирамина малеат 20мг, аскорбиновая кислота 50мг, парацетамол 325мг) однократно вечером; аскорбиновая кислота 850мг (шипучие таблетки) однократно на ночь. Дополнительно при головной боли - комплексный обезболивающий препарат (метамизол натрия 500 мг, питофенона гидрохлорид 5 мг и фенпивериния бромид 0,1 мг) до 3 раз в день.

Мониторирование своего состояния в условиях самоизоляции Пациент В. осуществлял самостоятельно с помощью Цифровой скрининговой интеллектуальной системы (ЦСИС) «Экраны Здоровья» http://www.healthscreens.ru/text.pdf:

1) модуль «Запас Энергии» http://www.powerreserve.ru/ осуществляет экспрессдиагностику состояния здоровья и рисков преморбидного фона с выделением критериев прогноза, выполняет инфекционный скрининг, определяет состояния базового метаболизма, а также величину биологического возраста и риск внезапной смерти; 
2) модуль «КиберЗдоровье» - система медицинского Искусственного Интеллекта, реализующая функцию физиологического описания эффективности функционирования систем кровообращения и дыхания, а также успешности эндокринно-метаболического регулирования;

3) модуль «Запас Здоровья» - база данных пользователя по результатам работы системы медицинского Искусственного Интеллекта;

4) модуль «КиберКонструктор» - спортивно-физкультурный Искусственный Интеллект, реализующий функцию построения индивидуальных программ физической активности в зависимости от состояния здоровья и процессов энергообеспечения жизнедеятельности конкретного индивидуума;

5) модуль «КиберГлавный» - база данных по результатам работы спортивнофизкультурного Искусственного Интеллекта.
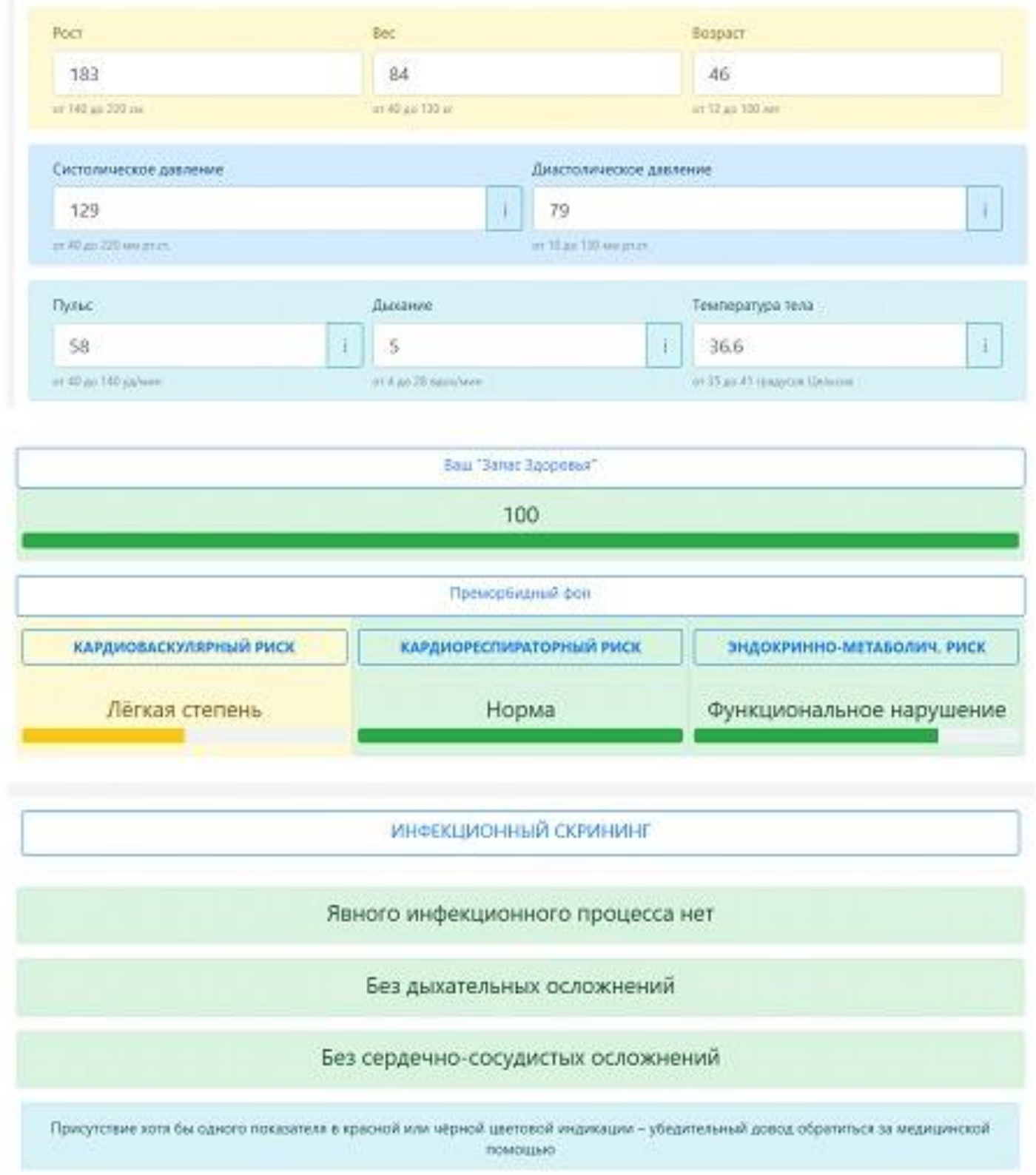


\begin{tabular}{|c|c|c|c|}
\hline \multicolumn{2}{|c|}{ 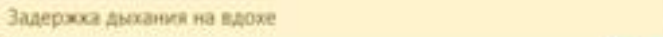 } & \multicolumn{2}{|l|}{ Cramveccaа балансироека } \\
\hline 100 & i & 60 & $i$ \\
\hline ers. & & or 0 as $120 \mathrm{~cm}$ & \\
\hline \multicolumn{4}{|c|}{ 3anontratb arkety } \\
\hline
\end{tabular}

Mnacxc uacere tena

Избыточный вес - 1

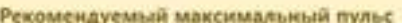

\section{9 уд/Мин}

Биомогический возраст

33

\section{Осковной общен}

1819 ккал/день

\section{Periculum morti}

\section{Минимальный}

\section{Параметр}

АДсис

АДдиа

чCC

чД

$\mathrm{MOCa}$

MOCB

yOa

yOs

OПСС $6 \mathrm{k}$

ОПСС мк

ОЦК

ИCCA

ИЛА

ИЭМо

ИMT

KAБM

КЯД

КСД

Одв

\section{Заключение}

Артериальная нормотензия

Диастолическая нормотония

Нормокардия

Отличная функция внешнего дыхания

Повышение минутной продуктивной работы сердца по лЖ

Удовлетворительная минутная продуктивная работа сердца по ПЖ

Нормальный левожелудочковый сердечный выброс

Нормальный правожелудочковый сердечный выброс

Удовлетворительная функция микрососудов БКК

Удовлетворительная функция микрососудов МКК

Нормоволемия

Удовлетворительная сердечно-сосудистая адаптация

Удовлетворительная лёгочная адаптация

Удовлетворительный эндокринно-метаболический гомеостаз (медленный тип)

Избыточный вес I

Удовлетворительный базовый метаболизм

Удовлетворительное состояние механизмов долговременной адаптации

Умеренный кардиоваскулярный дисбаланс

Оптимальное состояние индивидуального здоровья 
13.04.2020 - первый день заболевания. Сухой непродуктивный кашель. Лёгкая слабость. К вечеру температура до $37,3^{\circ} \mathrm{C}$. Зарегистрировано повышение артериального давления до 147/90 мм рт.ст., повышение частоты пульса до 64 bpm и частоты дыхания до 8 rpm.
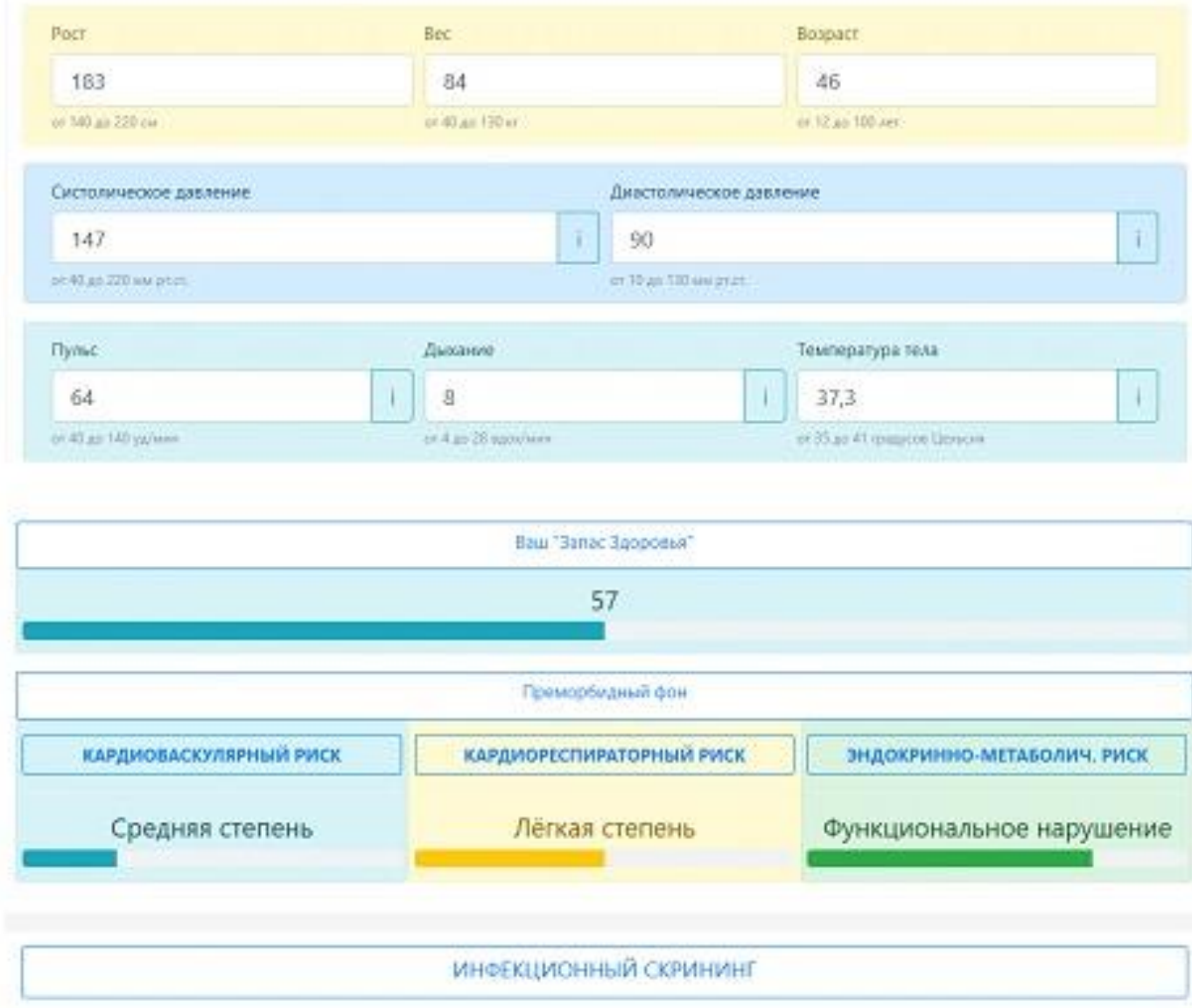

лёгкая форма инфекционного процесса

Без дыхательных осложнений

Лёгкая недостаточность кровообращения (функциональная)

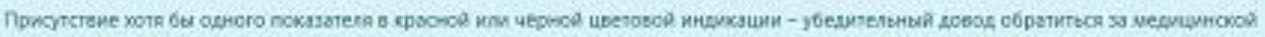
nowoutse

При мониторировании зарегистрировано ухудшение показателей здоровья, наличие инфекционного процесса в лёгкой форме с функциональной недостаточность кровообращения, но без дыхательных осложнений. 


\begin{tabular}{|c|c|c|c|}
\hline Параметр & & & Заключение \\
\hline Allone & 147 & мas pr. Сt. & Лёкая артериальная гипертензия \\
\hline AMana & 90 & мм pr. ст. & легкая диастолическая rипертония \\
\hline 4CC & 64 & УА/Мин & Нормокардия \\
\hline $4 / 2$ & 8 & $3 \mathrm{xe} / \mathrm{Mnn}$ & Отличная фунхция внешнего Аьхания \\
\hline MOCa & 6.7 & N/MиH & Значительное повышение минутной продуктивной работы сердца по ЛЖ \\
\hline $\mathrm{MOC} 8$ & 5.8 & N/Мй & Удовлетворительная минутная продуктивная работа сердца по ПЖ \\
\hline yoa & 1.16 & $6 / 6$ & Повышенный левожелудочковый сердечный выброс \\
\hline yos & 1.13 & $6 / 8$ & Нормальный правожелудочковый сердечный выброс \\
\hline OחCC 6k & 823 & AИH CM C.5 & Удовлетворительная функция михрососудов БКК \\
\hline OnCC MK & 784 & AUH CM C.5 & УАоелетворительная Функция михрососудов МКК \\
\hline ОцК & 103 & $\%$ & Умеренная rиперволемия \\
\hline MCCA & 0.49 & eA. & Снижение сердечно-сосудистой адаптации \\
\hline ИЛА & 0.63 & eA. & Удовлетворительная лёгочная адаптация \\
\hline И3MO & 1.27 & eA. & УАовлетворительный зндокринно-метаболический гомеостаз (медленный тип) \\
\hline ИMT & 25.1 & eA. & Избыточный вес I \\
\hline KASM & 1.1 & eA & 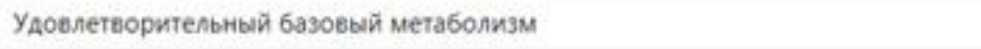 \\
\hline KRA & 1.23 & eA. & Умеренная кардиореспираторная дисфункция \\
\hline KCA & 0.74 & eA. & Кардиоеаскулярный синдром легкой степени \\
\hline ОДВ & 49 & $\%$ & Состонние индивидуального здоровья нике среднего уровня \\
\hline
\end{tabular}

Из функциональных отклонений - значительное повышение продуктивной работы по левому желудочку сердца (6,7 л/мин), развитие лёгкого кардиоваскулярного синдрома. Состояние индивидуального здоровья - ниже среднего уровня (Общая дезадаптационная вероятность (ОДВ) составила 49\%).

14.04.2020 - второй день заболевания. Состояние резко ухудшилось. Температура тела поднималась до $38,3^{\circ} \mathrm{C}$. Характер повышения температуры носил гектический характер, хорошо купировался приёмом аспирина и парацетамола. Стали беспокоить отсутствие аппетита и тошнота. Появилась постоянная головная боль, плохо купируемая приёмом анальгетиков. Артериальное давление утром составляло 145/80 мм рт.ст. с пульсом 56-61 bpm. Во второй половине дня артериальное давление составляло уже 160/80 мм рт.ст. с пульсом $60 \mathrm{bpm}$. Частота дыхания при этом составляла $7 \mathrm{rpm}$. По-прежнему сухой непродуктивный кашель.

Для нормализации артериального давления была использована физиотерапевтическая процедура - кратковременное (2-3 мин) пропаривание стоп горячей водой. 

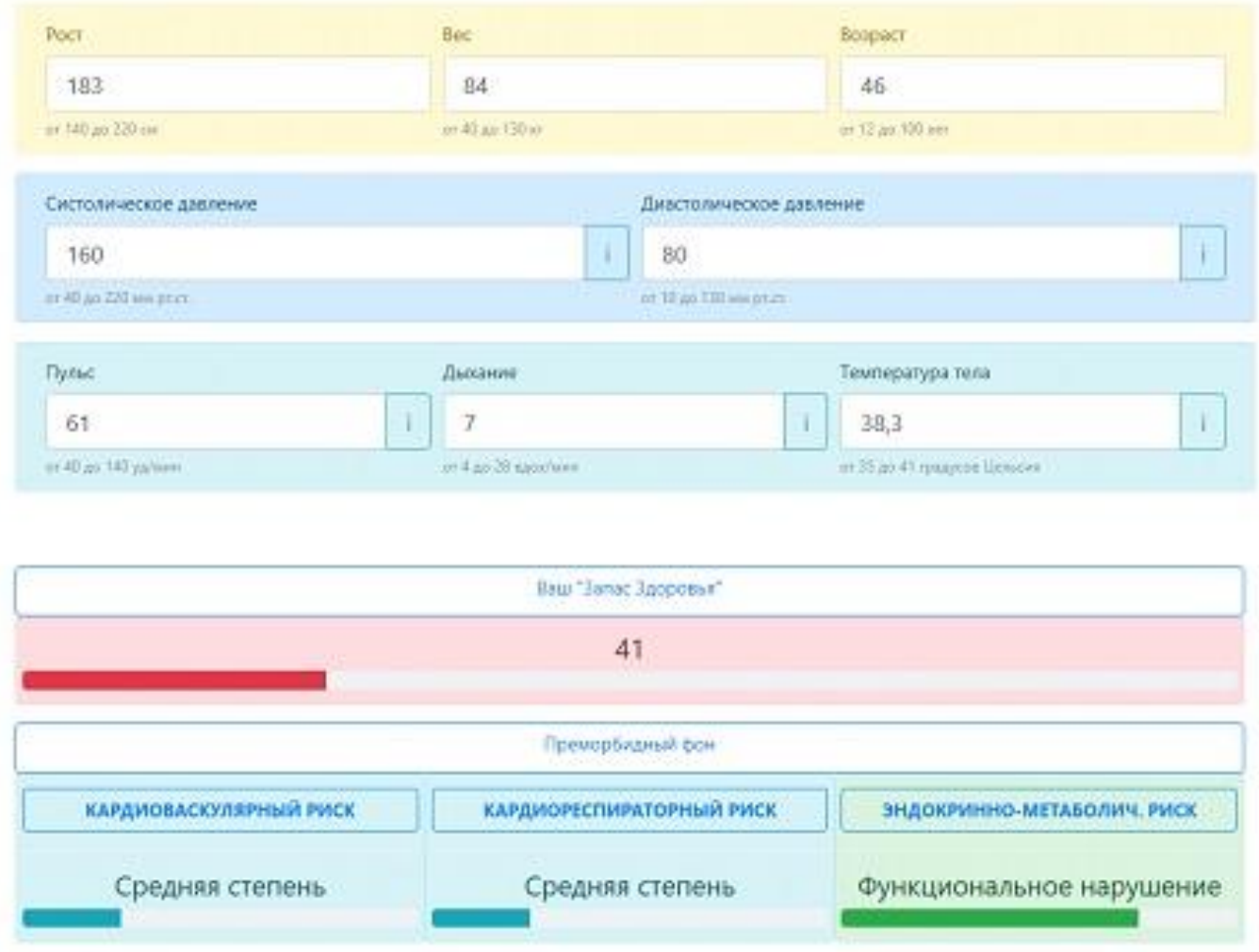

ИНФЕКИОНнЫЙ СКРИнИНг

Инфекционный процесс средней тяжести

Лёгкая дыхательная недостаточность

Недостаточность кровообращения средней степени

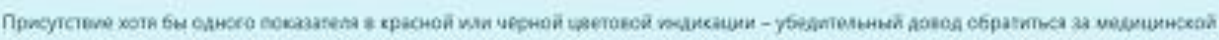
nomsuphs

Результаты мониторирования показали статистически значимое ухудшение показателей здоровья на фоне развития инфекционного процесса средней тяжести с выраженной недостаточностью кровообращения и признаками дыхательной недостаточности. 


\begin{tabular}{|c|c|c|c|}
\hline \multicolumn{3}{|l|}{ Параметр } & \multirow{2}{*}{$\begin{array}{l}\text { Заключснис } \\
\text { Артериальная гипертензия средней тякести }\end{array}$} \\
\hline Adicne & 160 & MM pt. ct. & \\
\hline АДдиа & 80 & MM pt. cr. & Диастолическая нормотония \\
\hline $4 C C$ & 61 & УА/Мин & Нормокардия \\
\hline $4 Д$ & 7 & эKC/Mин & Отличная Фуккиия вмешкето дыхания \\
\hline $\mathrm{MOCa}$ & 6.9 & A/Mne & Значитеаьное повышение минутной продуктивной работы сердца по ЛЖ \\
\hline $\mathrm{MOCB}$ & 7 & A/Mnn & Змачительное повышение минутной продуктиеной работы сердиа по ПЖ \\
\hline YOa & 1.22 & $6 / 8$ & Повышенный левохелудочховый сердечный выброс \\
\hline yOe & 1.42 & $6 / 8$ & Значительное повышение правожелудочкового сердечного выброса \\
\hline oncc $6 x$ & 804 & АИМ CM $\mathrm{C}^{-5}$ & Удовлетворительная Фунхиия михрососудов БКК \\
\hline once mk & 805 & АИн СМ $\mathrm{C}^{-5}$ & Удовлетворительная функция микрососудов МКК \\
\hline OUK & 112 & $\%$ & Выраженная гиперволемия \\
\hline ИCCA & 0.44 & eA. & Спикение сердечно-сосудистой адаптации \\
\hline ИЛА & 0.58 & eA. & Повынение «воздушностиь лёгочной ткани \\
\hline ИЭМ० & 1.24 & eA. & Удоелетворительный зндокринно-метаболичесхий томеостаз (медленный тип) \\
\hline ИMT & 25.1 & eA. & Избыточный вес। \\
\hline KASM & 1.09 & eA. & Удовлетворительный базовый метаболизм \\
\hline KRA & 1.29 & eA: & Кардиореспираторный синдром лёгкой степени \\
\hline KCA & 0.66 & eA. & Кардиоваскулярный сикдром лёгкой степени \\
\hline$O A B$ & 64 & $\%$ & Низкий уровень индивидуального здоровья \\
\hline
\end{tabular}

При функциональном скрининге была зарегистрирована выраженная гиперволемия (112\%), значительное повышение минутных объём сердца (6,9 и 7,0 л/мин), значительное повышение правожелудочкового сердечного выброса $(1,42$ б/в), что является патогномоническим признаком развития лёгочной гипертензии. Снижение сердечнососудистой адаптации с развитием кардиореспираторного и кардиоваскулярного синдромов лёгкой степени тяжести. Низкий уровень индивидуального здоровья (ОДВ возросло до $64 \%)$.

Вечером Пациент В. отметил частое и обильное мочеиспускание, которое заставило его подниматься ещё четыре раза ночью, как после приёма мочегонных препаратов.

15.04.2020 - третий день заболевания. Утром Пациент В. отметил улучшение самочувствия. Температура тела субфебрильная $-37,1-37,3^{\circ} \mathrm{C}$. Артериальное давление составило 142/82 мм рт.ст., пульс - 56 bpm, дыхание - 6 rpm. Кашель стал интенсивнее, но значительно реже. По-прежнему сухой, непродуктивный. Аппетита нет, но тошнота и головная боль беспокоят незначительно. Вес снизился до 83,5 кг. 

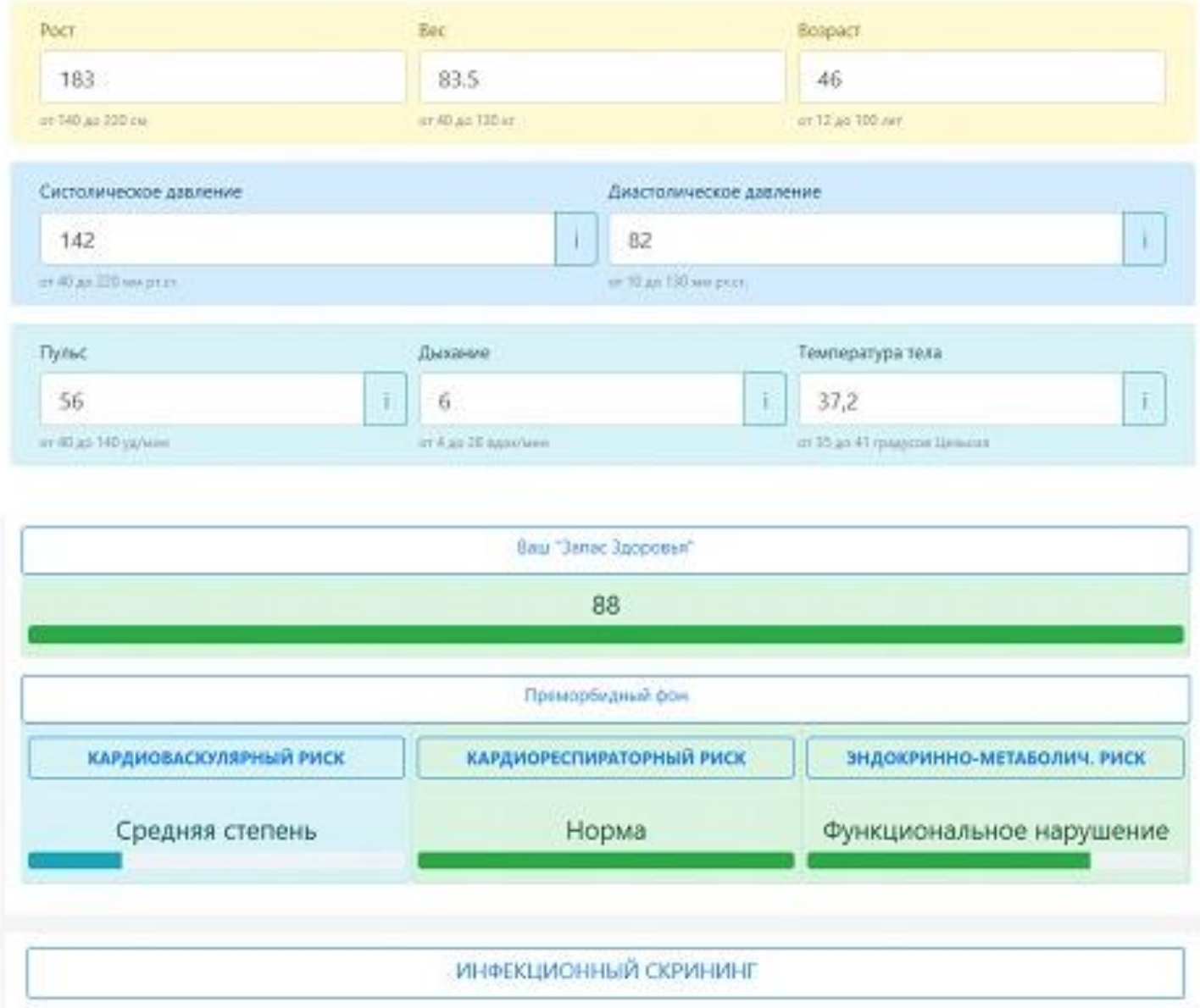

Лёгкая форма инфекционного процесса

Лёгкая дыхательная недостаточность

Без сердечно-сосудистых осложнений

При мониторировании - инфекционный процесс в лёгкой форме с лёгкой дыхательной недостаточностью без сердечно-сосудистых осложнений. 


\begin{tabular}{|c|c|c|c|}
\hline Параметр & & & Заключение \\
\hline AdCuc & 142 & мм рт. ст. & Лёгая артериальная гипертензия \\
\hline Aдnиa & 82 & мм рт. ст. & Лёгкая диастолическая гипертония \\
\hline $4 C C$ & 56 & УА/Мин & Нормокардия \\
\hline $4 \Delta$ & 6 & экС/мин & Отличная функция внешнего дьххания \\
\hline MOCa & 6.5 & ת/MUH & Повышение минутной продуктиеной работы сердца по ЛЖ \\
\hline MOCB & 5.8 & л/мин & УАовлетворительная минутная продуктивная работа сердца по ППЖ \\
\hline yoa & 1.22 & $6 / 8$ & Повышенный левожелудочковый сердечный выброс \\
\hline yoe & 1.26 & $6 / 8$ & Повышенный правожелудочковый сердечный выброс \\
\hline once $6 k$ & 739 & Аин $\mathrm{CM} \mathrm{C}^{-5}$ & УАОвлетворительная функция микрососудов БКК \\
\hline oncc mx & 714 & дин См $\mathrm{C}^{-5}$ & УАовлетөорительная функция микрососудов МКК \\
\hline OLK & 100 & $\%$ & Нормоволемия \\
\hline UCCA & 0.46 & eA. & Снижение сердечно-сосудистой адаптации \\
\hline ИЛА & 0.53 & eA. & Повышение «воздушности лёгочной ткани \\
\hline ИЭМо & 1.19 & eд. & УАовлетворительный эндокриняо-метаболический гомеостаз (медленный тип) \\
\hline ИMT & 24.9 & eA. & Нормальный вес \\
\hline KA5M & 1.07 & eA. & УАовлетворительный базовый метаболизм \\
\hline Кяд & 0.97 & eA. & УАовлетворительное состояние механизмов долговременной адаптации \\
\hline KCA & 0.73 & eA. & Кардиоваскулярный синаром лёгкой степени \\
\hline ОДВ & 17 & $\%$ & Высокий уровень индивидуального здоровья \\
\hline
\end{tabular}

Функциональный статус с положительной динамикой - нормоволемия (100\%), удовлетворительная минутная продуктивная работа по левому желудочку сердца (5,8л/мин), но с сохранённым повышением сердечного выброса по обоим желудочкам $(1,22$ и 1,26 б/в). Сохраняется кардиоваскулярный синдром лёгкой степени. Общая дезадаптационная вероятность показала положительную динамику прироста уровня индивидуального здоровья.

Однако во второй половине дня самочувствие снова ухудшилось: температура тела поднялась до $37,8^{0} \mathrm{C}$, артериальное давление при этом стало 150-160/85-90 мм рт.ст., пульс - $61 \mathrm{bpm}$, дыхание $6 \mathrm{rpm}$. Головная боль и тошнота усилились. Для нормализации артериального давления снова была использована физиотерапевтическая процедура кратковременное (2-3 мин) пропаривание стоп горячей водой. А также горячий имбирнолимонный чай.

Тем не менее, артериальное давление продолжало удерживаться на уровне 160/90 с пульсом 77 bpm, число дыханий - 7. Был назначен эналаприла малеат 2,5мг внутрь. После чего давление вышло на цифры 130/80 мм рт.ст. с пульсом 64 bpm, число дыханий - 6.

16.04-19.04.2020 года - четвёртый-седьмой день заболевания. Состояние Пациента В. оценивалось ближе к удовлетворительному. Периодические подъёмы температуры до $37,1-37,4^{0} \mathrm{C}$ (2-4 раза в день) купировались приёмом аспирина и парацетамола. Артериальное давление 140/90 мм рт.ст., пульс - 56-66 bpm, дыхание 5-7 rpm. Кашель сухой непродуктивный. Утром 16 апреля Пациент В. отмечал симптом «извращения вкуса», но это был однократный эпизод на один продукт (сырокопчёная колбаса в бутерброде показалась невероятно солёной настолько, что невозможно было её съесть). 


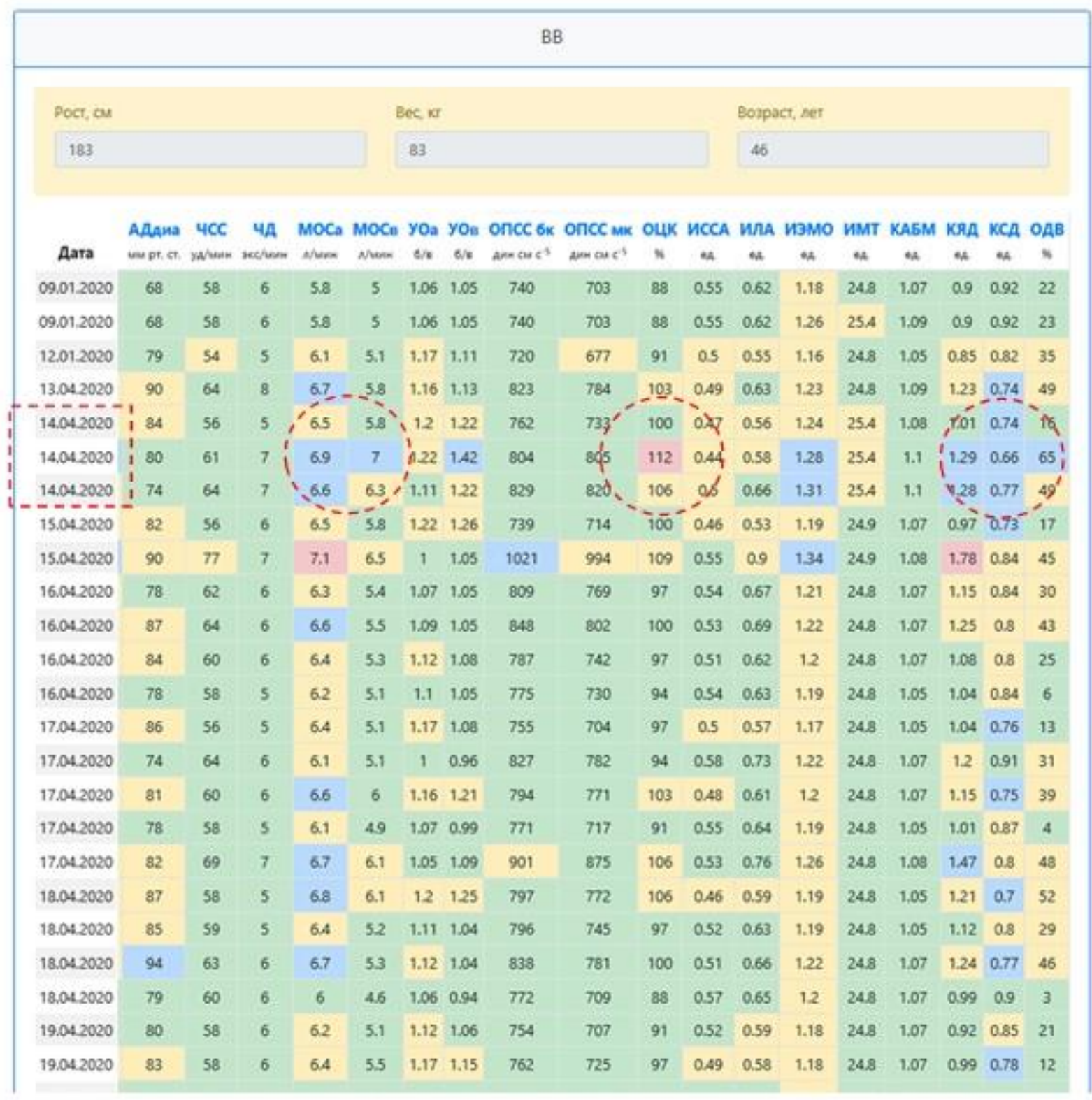

На рисунке представлена база клинических данных, полученная при мониторировании показателей здоровья Пациента $\mathrm{B}$. цифровой скрининговой интеллектуальной системы «Экраны Здоровья». Красными окружностями выделены клинические признаки-предвестники развития «ковидной» пневмонии - острого респираторного дистресс-синдрома. 


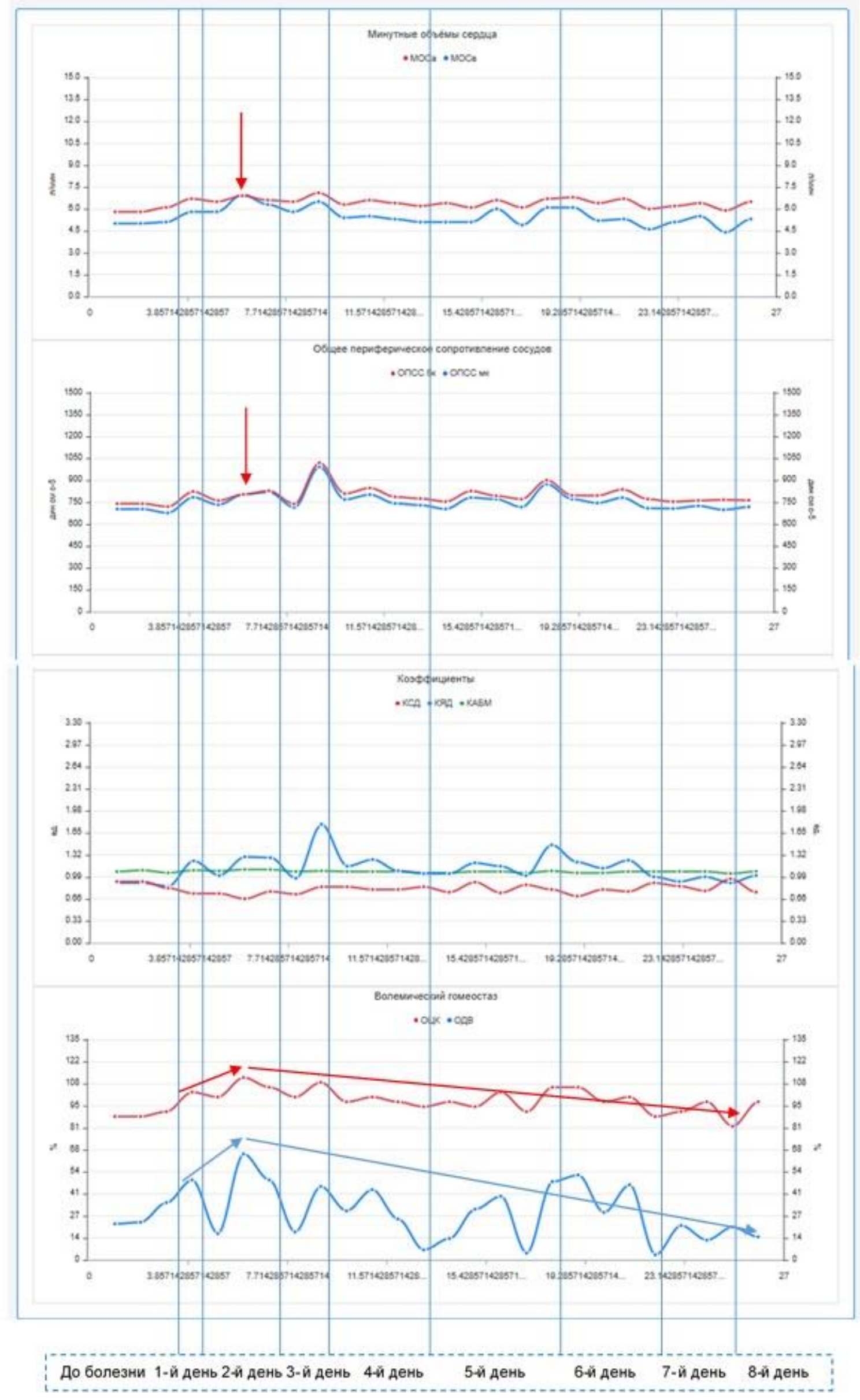


На рисунке представлены мониторинговые кривые показателей здоровья Пациента В., полученные с помощью цифровой скрининговой интеллектуальной системы.

Превышение абсолютных величин минутного объёма сердца правого желудочка сердца (МОСв) в сравнении с минутным объёмом левого желудочка сердца (MOCа) является чётким патогномоническим признаком развития лёгочной гипертензии, которая на фоне высокой температуры тела (более $38,0^{\circ} \mathrm{C}$ ) чётко охарактеризовало риск развития «ковидной» пневмонии - острого респираторного дистресс синдрома.

Однако «спортивный-физкультурный» бэкграунд Пациента В., отсутствие хронических заболеваний и тяжёлой формы эндокринно-метаболического отягощения не допустили срыва механизмов адаптации, несмотря на исключительно симптоматическое амбулаторное лечение в домашних условиях.

К 8-му дню заболевания наметилась тенденция снижения величин общей дезадаптационной вероятности (ОДВ) и переход от гиперволемического статуса к нормоволемическому (показатели ОЦК).

Температура тела нормализовалась. Пациентом В. отмечается чувство заложенности в грудной клетке в проекции трахеобронхиального дерева, больше справа. Жалобы на быструю утомляемость, потливость.

В реабилитационном периоде к астено-невротическому состоянию присоединились увеит правого глазного яблока, обострение слипчивого арохноидита, вызванного военной тяжёлой черепно-мозговой травмой, тяжёлая вертебро-базиллярная недостаточность.

Для разработки персональной программы реабилитации Пациентом В. использовался модуль «КиберКонструктор», реализующий функцию построения индивидуальных программ физической активности в зависимости от состояния здоровья и эффективности процессов энергообеспечения жизнедеятельности.

Полная программа реабилитации после перенесённого COVID-19 у Пациента В. заняла 2,5 месяца. Достигнуто восстановление функционального состояния до уровня не менее $97 \%$.

На рисунках представлены итоги выполнения персональной 2,5 месячной программы реабилитации, разработанной для Пациента В. модулем «КиберКонструкор». 
Si glissader@yandex.ru Выход

Кибернетический физкультурно-спортивный конструктор

(тренировки на выносливость)

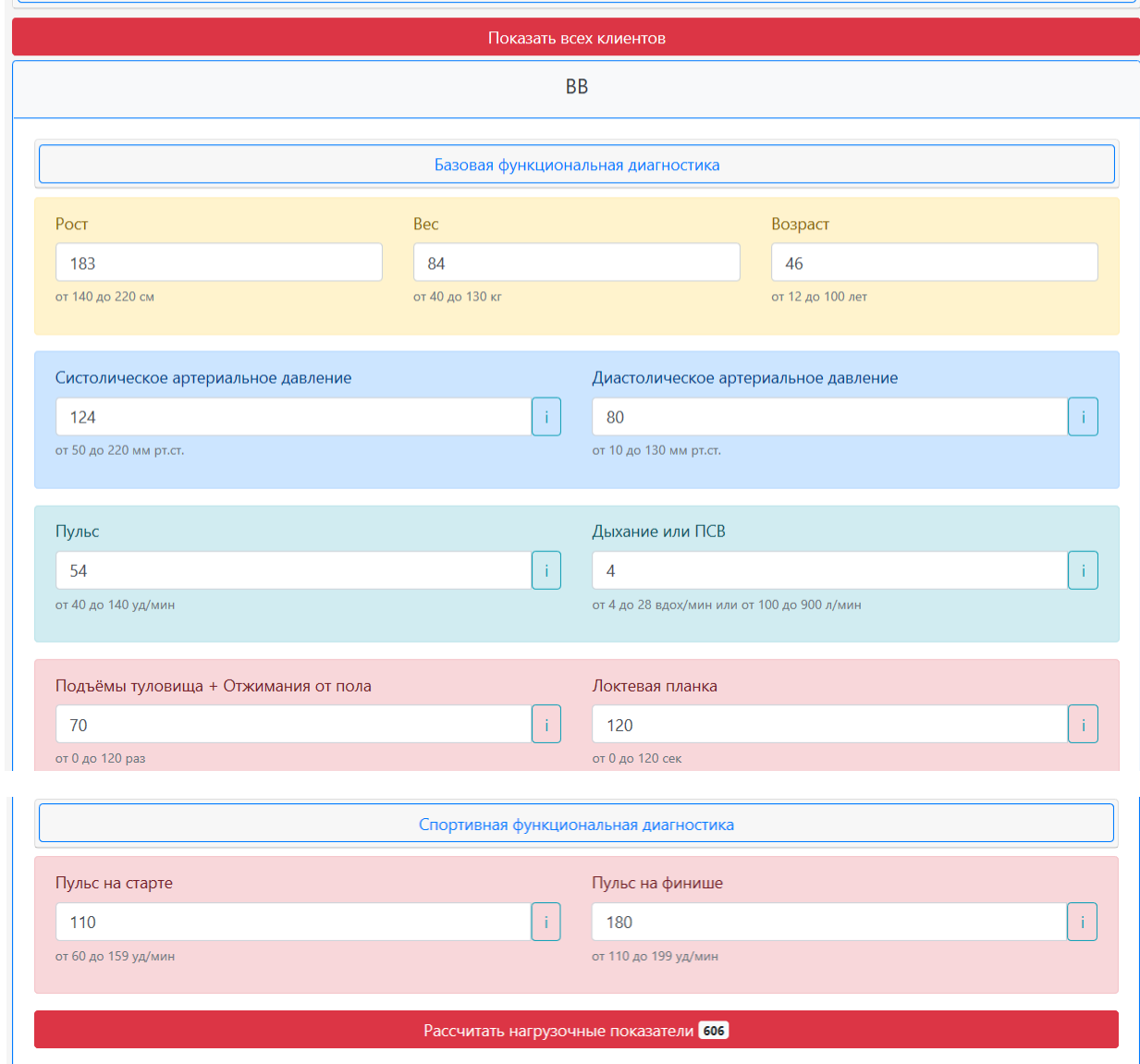
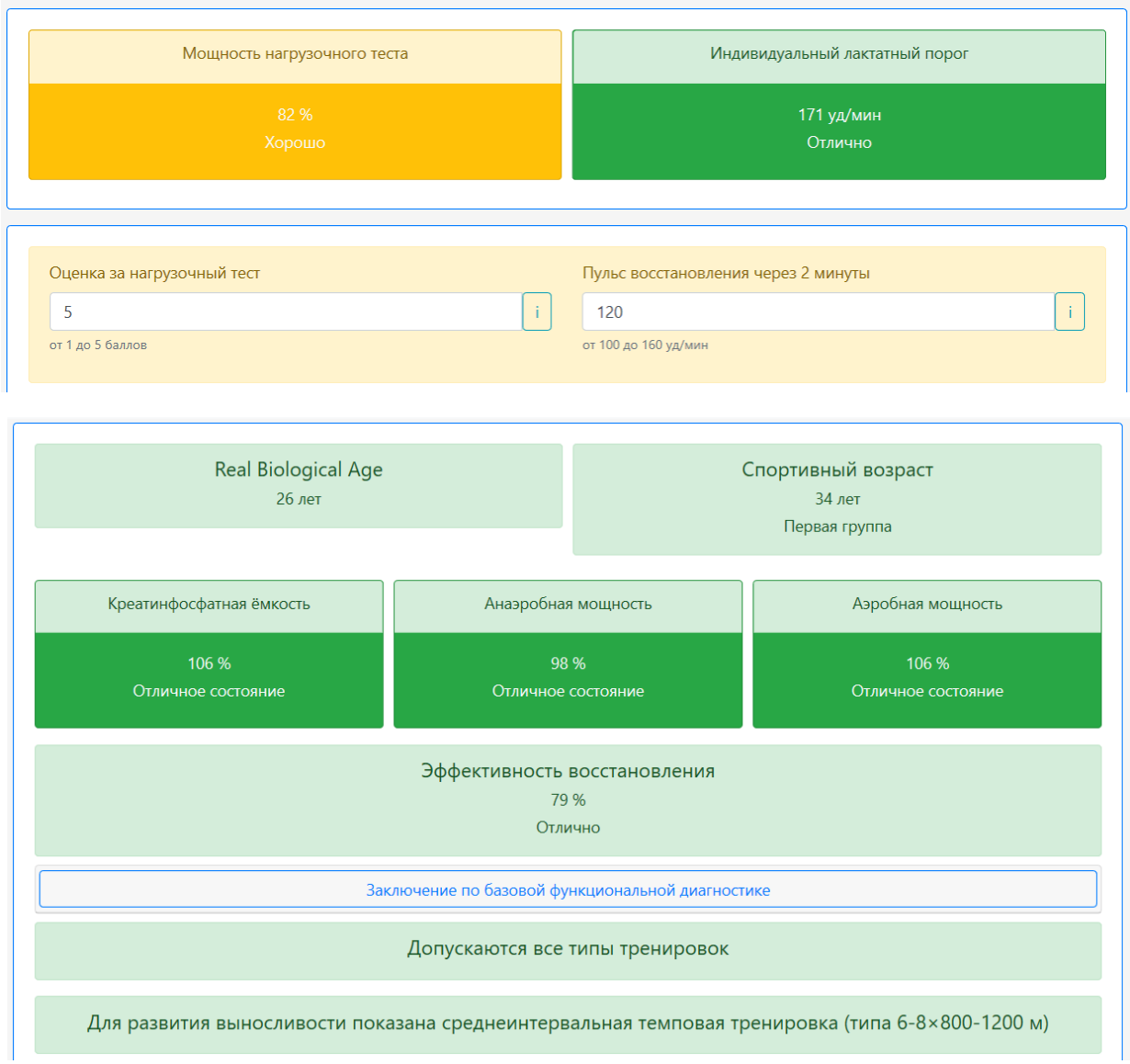
Уровень функциональной подготовленности

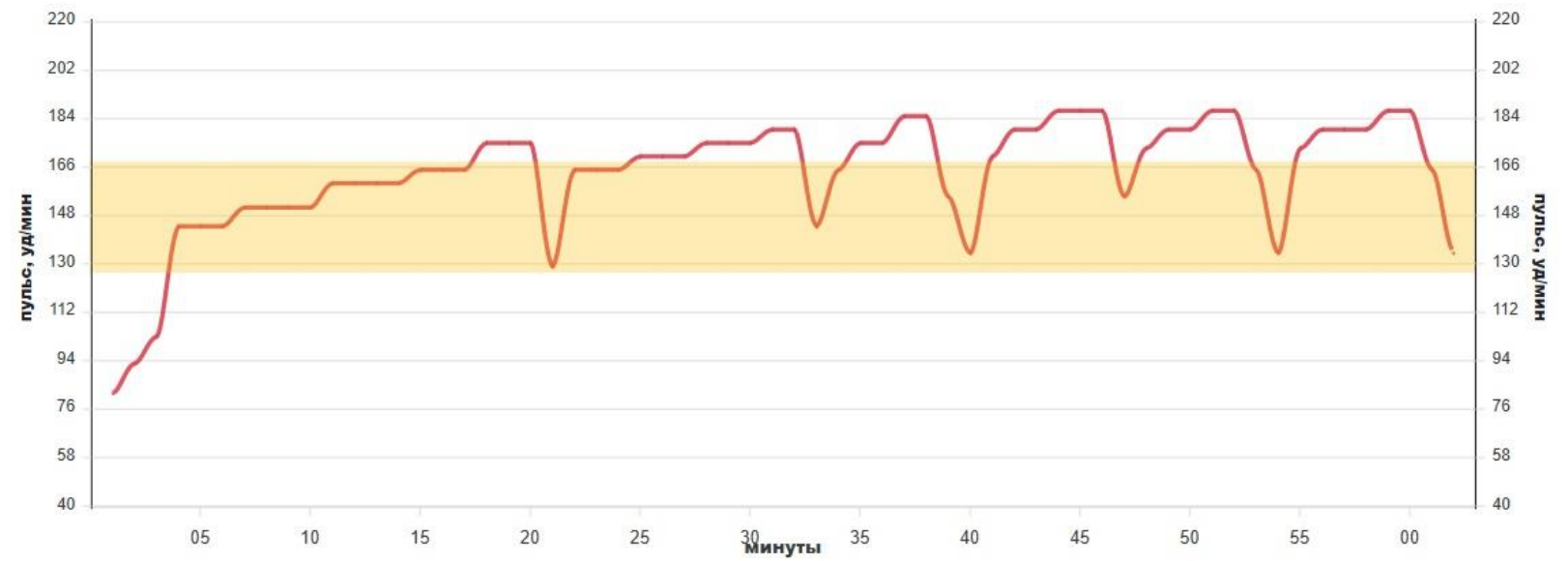

\section{Заключение}

Ведущей причиной развития осложнений при COVID-19 являются гемодинамические расстройства, требующие перманентного мониторингового контроля со стороны медицинского персонала. В условиях пандемии COVID-19, когда ведущей проблемой становится острая нехватка сил и средств медицинской службы для оказания квалифицированной помощи пациентам с тяжёлой формой этого заболевания, наличие цифровых телемедицинских средств контроля за состоянием здоровья пациентов типа ЦСИС «Экраны Здоровья» позволяет осуществлять эффективное лечение лёгких и среднетяжёлых форм коронавирусной инфекции у молодых людей и людей среднего возраста без вредных привычек и сопутствующих заболеваний в домашних условия с последующей разработкой для них персональных программ реабилитационных мероприятий.

\section{Список литературы}

1. Савостьянов В.В., Особенности клинического течения COVID-19 // "Научный Журнал", №4(49), 2020 - c.69-71

\section{https://scientificmagazine.ru/images/PDF/2020/49/Nauchnyj-zhurnal-4-49-.pdf}

